\title{
Students' Attitudes and Perceptions of ICT: Weblog Application in Improving Methods of SCL on Writing Class 2: Online Exploration of Global Issues
}

\author{
Marleiny Radjuni \\ Hasanuddin University, Indonesia \\ Correspondence: marleinyradjuni@unhas.ac.id
}

\begin{abstract}
In this digitized era, English as a Foreign Languag (EFL) teachers in Indonesia, as in many other countries are anxious to exploit the potential of Information and Communication Technology (ICT) to enhance the teaching and learning process. Given the increasing pressure exerted by technological developments on language education, it is important to understand the underlying factors behind teachers' decisions regarding ICT. Regarding this matter, this study investigates the development as well as the effects of ICT applied in English Department in teaching and learning process. The use of weblog is being applied in the Academic Writing classes for a couple of years now. Students are equipped with the method of teaching through blog. So far, the use of ICT in the classroom often part of a teacher-centered class but it is easy to exploit these tools in learner-centered activities. For this particular case, students have freedom to control themselves in using the internet technology, even though it is still under teachers instructions. The method applied in this study is combination of the qualitative and quantitative. Evidence has been collected through a literature search, students questionnaires and semi interviews designed. The factors which was found to be most importans to these students were; having the lesson more interesting, easier, more fun for them, more diverse, more enjoyable and on top of that is more motivating.
\end{abstract}

ARTICLE HISTORY

Published June $2^{\text {th }} 2021$

Check for updates

\section{KEYWORDS}

Attitudes And Perceptions, ICT, Weblog,

\section{ARTICLE LICENCE}

(C) 2021 Universitas Hasanuddin Under the license CC BY-SA

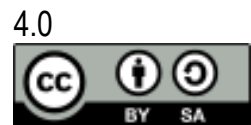

\section{Introduction}

Nowadays, the use of Internet technology in the world is increasing. Almost everyone has definitely enjoy Internet services. Formerly the Internet is only used by workers in the field of Internet-based computing technology and those who understand that technology alone. Along with the times, technology is also progressing towards the achievement of remarkable ease and comfort in performing everyday activities that are considered impossible to be done in a short time, as well as in the learning process.

The technology is currently the fastest development of information and communication technology (ICT) that presents a diverse selection of technologies and sophistication (Junaidi, et al., 2020a). Internet is one proof the rapid technological developments in the field of information and telecommunications. It brings an enormous influence on the life pattern of the world community in general, particularly the developed countries also called the Internet world without limits because it is truly global. Time and distance is no longer a problem to get information or provide information. Although still lagging behind, Asian countries are more advanced, the development of the Internet in Indonesia has shown significant development. Indeed, Internet has become the information center in the world. In fact there are some people who do not utilize the functionality of the Internet. Some people have difficulty in finding information because of language barriers though a variety of interests and education work relies on the Internet. All it requires each individual to be able to operate the Internet as a consequence of living in this sophisticated era. Internet as a medium of learning began to be applied to the world of education.

In the world of education, especially in the learning process, there are two elements that are considered important and is believed to affect the outcome of the learning methods of teaching and learning media. Both of these aspects are interrelated. Selection of one particular "teaching method" will affect learning appropriate media type, although there are other aspects that must be considered in selecting instructional media, among others, learning objectives, types of tasks 
and the expected response of students including student characteristics. Nevertheless, it can be said that one of the main functions of a medium of learning is as a "teaching tool" that also affect climate, conditions and learning environment organized and created by teachers.

The use of instructional media in teaching and learning can generate new interest and desire, the motivation and stimulation of learning activities and even bring psychological influences that are positive towards students. The use of instructional media in teaching orientation phase will greatly help the effectiveness of the learning process and the delivery of messages and content at the time.

No doubt, today's media has become part of life for humans. In developed countries, the media has affected most of the time a person's life. In the world of education and learning, the role of the media cannot be overlooked. As one component of learning, media cannot escape discussion learning system as a whole. The use of the media is a part of that should get the attention of lecturers in each learning activity. But the reality is this part that is often overlooked by many reasons. The reason often arise among other things; limited time to make preparations to teach, hard to find the right media, unavailability costs, and others. It is unnecessary if every lecturer has equip themselves with knowledge and skills in terms of learning media.

Then in addition to that, if learning is a process of processing a number of values for consumption by students verily those values can be taken from a variety of sources. The comprehensive learning resources in many and could actually found everywhere. Of the many components in the learning, learning resources play a role in assisting the faculty in enriching students. With the use of information technology as a learning resource in the learning process, the faculty and students are challenged to be more creative in the learning process and digest the material. Books in the form of printed media were now replaced with the name e-book.

One of the interesting phenomena of the Internet is a blog. Blog originally just a private site that includes a collection of links favorite sites and their owners tend to only as a merely diary online. But as the popularity of its appeal has now been developed into a blog or news source of alternative information. This is due to the ease of manufacture is WYSWYG (what you see is what you get), without the need for complex programming language. As an alternative media and learning resources, blog assessed strategic enough additional material to enrich the learning. With the blog that can be accessed anytime and anywhere, the learning process does not stop just in the classroom. At home, or in the cafe that has Internet access, students can continue learning by reading or writing that is given by the lecturer through the blog, and also discussed there. Based on these opinions, it can be concluded that the quality of learning will increase if the lecturer is able to create the conditions of learning that is active, creative, and effective communication interactions of faculty and students with the application of a blog as a means to further improve the quality of learning itself and also the quality of language students in particular, by using one of the appropriate learning media, namely blogs.

Learners particularly in the English Department, Faculty of Cultural Sciences, Hasanuddin University (Unhas) has been using the Internet for everyday purposes, especially in the learning process. One of the activities that require the use of Internet in teaching and learning is teaching based on SCL (Student Center Learning) using the weblog at Writing class 2. In relation to this, this study was set up to investigate the attitudes and perceptions of students to ICT in implementing weblog application in order to improve the effectiveness of the learning process that based on SCL (Student Center Learning) at Writing class 2 in the Department of English, Faculty of Cultural and Science, Unhas.

In addition, the purpose of this paper is to present the findings of the research results relating to the uptake of ICT in teaching Writing with SCL approach.

\section{Problem Formulation}

Based on the background of the problems mentioned above, this research focused on the following principal issues;

a. What are the students' attitudes and perceptions towards the use of ICT (the use of weblog in particular)?

b. Whether the application of weblog with SCL learning approach can further improve the quality of graduates majoring in English Department?

\section{Objectives}

Based on the formulation of the problem, the objectives to be achieved in this study are as follows. a) To find an increase in activity of learning by applying the weblog with SCL learning approach can increase the activity of learning in learning Writing, and b) To determine the improvement of the quality of graduates Department of English by applying SCL weblog through this learning approach. 
This study aims to provide insight into the theoretical and practical knowledge for professors related to the use of Internet technology in this case represented weblog. Because of the lack of attention to the lecturers of English on the use of technology in teaching either as an enrichment method, as a medium of learning, as a source of learning and teaching strategy it is expected that through this research can eliminate technical obstacles that arise and objectively indeed faced by lecturers and of course also to inspire them to be able to make a learning method with the approach weblog. Therefore, this study are expected to provide insight into the knowledge, skills and inspiration for professors of English to be able to further optimize the development and sophistication of information communications technology (Internet, weblogs and social networks) in order to improve the quality of learning, especially in the English Department. Other than that, this study also examines the methods of learning appropriate to enhance the activity of learning so that the quality of graduates will also be increased. Thus the findings of this study will enrich the knowledge in the field of learning methods.

In practical terms, this research is oriented on learning technology products such as making weblog that contains content related to the Writing 2 materials which is not useful only for students but also for the lecturers who overflow the course skills. From this research, students gain a more meaningful learning experience, so that they become more controlled and skilled in problem solving learning with application of the method of using a weblog application using SCL learning approach so that students can enhance the activity of learning and can also produce higher quality graduates. Besides that, students can increase the motivation to learn the language especially academic writing. For lecturers, information and research results is expected to be me valuable in making every effort to improve the quality of the learning process through a weblog and certainly make improvements to the learning process. In addition, the results of this study can be useful information for the Head of Department to take out a policy that is most appropriate in connection with efforts to present the learning strategies that effectively and efficiently in English Department.

\section{Basis Theory}

In this globalization era, a paradigm shift in the world of education. Education that took place today at least two significant challenges. The first challenge comes from the change in the outlook of the learning itself. The views behaviorism prioritizing stimulus and response is not enough to be able to provide optimum results. Besides those involved in education is more interested in the cognitive and affective aspects of students, or more precisely how and what happens when students learn dynamically, including internal and external factors what affects their way of thinking or learning.

For now teaching in the English Department in particular has led to a constructive view which states that any practice of learning an absolute must involve activities that support all students to improve and develop skilled analytical and critical reasoning, problem solving, communication skills, and achieve the habit of thinking. Learning in English literature must also present the key ideas and concepts from various perspectives, such as presenting a wide range of examples and applications to motivate and illustrate the material, promoting the connection of a field of science to other disciplines, to develop the ability of each student to apply the material taught to the other disciplines, introducing the latest topics from a field of science and its applications, and improve the perception of the students about the vital role and importance of science and technology in the development of today's world.

The second challenge facing education today is the advancement of information and communication technology is so rapid, which offers various facilities for learning. These technological advances enable a shift in the orientation of outsided-guided learning be self-guided. Besides technology also plays an important role in renewing the original conception of learning that is solely focused on learning as a presentation of various knowledge into learning as a guidance to be able to explore the rich cultural and social knowledge. Updates paradigm of learning through constructivism outlook and shifts that occur because of the advancement of information and communication technology are two things that are very consistent and mutually reinforcing. Constructivism and technologies, separately or jointly offer new opportunities in the learning process, both in the classroom, distance and independent learning.

According to Rosenberg (2001), the use of ICT there are five shifts in the learning process, namely: (1) from training to performance, (2) from the classroom to, anytime and anywhere, (3) of the paper to the "on line", (4) of physical facilities to network facilities, and (5) of the cycle time to real time. Communication as a medium of education is done by using communication media such as telephones, computers, internet, e-mail, and so forth. Lecturers can provide service without having to deal directly with students. Similarly, they can obtain information in a wide range of different sources through cyber space or virtual space using computers or the Internet (Rahman, 2017). Here is the role of lecturers to create its own curriculum to make students learn actively.

The most recent is the development of so-called "cyber teaching" or virtual teaching, the teaching process is done using the Internet (Junaidi, 2020b) Another term that is increasingly popular today is e-learning is a model of learning by 
using ICT media, especially the Internet. According to Rosenberg (2001), e-learning is an extensive network which is based on three criteria: (1) e-learning is the network with the ability to renew, store, distribute and share teaching materials or information, (2) delivery to end users via a computer using standard Internet technologies, (3) focus on the most comprehensive view of learning beyond the traditional learning paradigm. In addition to the development of ICT's own understanding of e-learning is becoming more widespread is the practice of learning supported by technology services such as telephone, audio, video tape, satellite transmissions or computer.

Currently e-learning has evolved in a variety of learning models based on ICT such as: CBT (Computer Based Training), CBI (Computer Based Instruction), Distance Learning, Distance Education, LCC (Learner-Centered Classroom), WBT (Web-Based Training), etc. (Aswad, et al., 2019). Blog as a representation of latest developments in the world of Internet and it is free and easy to make - give it a chance so that the activities can be more attractive and interactive. Through blogs, sources of relevant material can be published to all parts that can be accessed by anyone. Thus the student difficulties in collecting the sources of information required in the learning process can be overcome. Therefore, the blog is one of the strategic learning media to enhance the learning process of active and interactive (Hamuddin, et al., 2020).

According to Bruner (as cited in Darsono) there are 3 levels of learning mode, namely: direct experience (enactive), the experience of pictorial images (iconic), and the experience of the abstract (symbolic. Direct experience (enactive) is working on, for example, the word "circle" is understood directly by make or drawing a circle at the second level or ironic (picture/image), said circle understood by looking at pictures, paintings, photos or movies. Although students have never made a circle they can understand the meaning of the circle through drawings, paintings, photographs or movies. Furthermore, on a symbolic level, the students read or hear the word "circle" and try to match it with the image of a circle or match them with their experience to make circular shape.

All three have experience of interacting in an effort to gain "experience" (knowledge, skills or attitudes) are new. The more senses participate tool for receiving and processing a material or information, the greater the likelihood that information can be understood and retained in memory. Edgar Dale (in Lee, et al., 2007) classifies learning experiences ranging from things that are the most concrete to the things that are the most abstract. The classification is widely followed by educators in determining what the appropriate tools for a particular learning experience. In a learning process, the media should not be absolute held by the teacher. That is, if the teacher in the learning process does not use any medium of learning is not going to say fail, because the primary process is how learners can learn well and achieve the objectives that have been defined previously. However, the use of instructional media will promote successful learning because of several advantages as follows; a) to provide a deeper understanding of the learning material is discussed, because it can explain the concepts that are difficult or complicated to be easier or simpler, $b$ ) to explain the learning material or abstract objects (not real, cannot be seen directly) into concrete (or real, can be seen, felt, or touched), c) To help teachers present learning materials to more easily and quickly, so that the students were easy to understand, longer remember and easy revisits the material being taught, d) Interest and generate interest, motivation, activity and creativity of learners. e) to stimulate the participation of learners in the process of leaning and leave a deep impression in the minds of learners, $f$ ) to establish a shared understanding and correct opinion to an object, because it is delivered not only verbally, but in the form of real use of instructional media, and g) Creating a conducive learning environment, so students can communicate and interact with the environment in which learning and provide real and immediate experience.

There are still many other ways that teachers can do to make student learning. The role of the lecturer is supposed to do is to see it that every student can interact actively with a variety of learning resources available. Other lecturers are one source of learning for students. In addition to teachers, there are many more sources of learning. On this basis, AECT (Association of Education Communication Technology) through his work The Definition of Educational Technology (AECT, 1977; Januszewski (2001) classified into 6 types of learning resources;

a. Message, that information is forwarded by the teachings of other components in the form of ideas, facts, meanings and data. Included in the message components are all subjects/courses or teaching material taught to students.

b. People ie human beings who act as storage, processing, and publishing a message, such as teachers, lecturers, students and so on.

c. Material, which is software that contains the message to be presented through the use of tools or hardware, or by itself, for example movies, audio, magazines, etc.

d. Device, which is something (hardware) used to convey the messages stored in material such as OHP, slides, radio, etc.

e. Technique, the procedure or reference prepared for the use of materials, equipment, people, environment to deliver the message, for example, simulations, demonstrations, question and answer, and so on. 
f. Setting (or environment), namely the situation or atmosphere where the message is delivered both physical and nonphysical environments, such as classrooms, libraries, etc.

In addition, the learning resources can be classified from other versions, namely: 1) According to its nature, learning resources there are 2 kinds of human resources (human) and non-human (non-human), and 2) According to the terms of the development of learning resources there are two kinds: Learning Resources by design (learning resources designed for teaching purposes) Learning resources by utilitarian (the learning resources that are not designed for teaching purposes) (Januszewski (2001)

According to Miftachudin (2017) the benefits of blog for lecturers among others, as proof of their professionalism related portfolios, the development of varied learning process, as a medium of teaching and learning, a place to discuss, communicate and share information. A relatively low cost and can penetrate the space and to develop a wider network between lecturers are hallmarks blog. Through blog the competence of lecturers are expected to increase. Through the faculty blog to show the subject matter that can be downloaded students, ideas, to get a link as a reference, assignments, and evaluation. Applications are available in the blog comments provide ease of interaction between students and professors. By having a blog misuse of the Internet by students can be minimized. They can write the pursuit of his goals, hobbies, poetry, short stories, or activities they carried out daily. It is because most of the students use blogs as their online diary.

\section{Methods}

To achieve the objectives of this study, the merger between quantitative and qualitative approaches will do. The percentages of both are $20 \%$ quantitative and $80 \%$ qualitative. Descriptive qualitative methods will be used to present the results of data analysis.

To be more structured, the research methods used in this study will be described as follows.

a. Area of Research: Which became the location of the data is the English Department of the Faculty of Cultural and Science, UNHAS

b. Research Subjects: 50 students from the fifth semester which will be the subject of this study. They will be selected at random to determine the validity of the data. They will be interviewed to make qualitative data. Surveys in the form of questionnaire will be performed at all samples to collect data on attitudes and their perceptions of the use of ICT, especially a weblog with SCL approach. The question posed in this survey is the elaboration of a Problem Formulation (Research questions) will be answered through this research.

\section{Data Collection Methods}

Data for this study will be collected for approximately two months in the Department. Multiple data sources to be used in the study were questionnaire, interview, classroom observations, field notes, as well as artifacts (documents). Merging of multiple data sources will enable the achievement of data enrichment. The adoption of a wide range of sources and types of data triangulation enabled data to be Achieved. Here will be briefly described the types of the data collection.

\section{a) Questionnaire:}

To obtain accurate data on study subjects, questionnaires are designed with a load of questions about the information that is directly related to the formulation of the question in the formulation of the problem. Interview:

The second instrument will be used in this research is interview. Two (2) sets of questions prepared aims to collect data on the attitudes and perceptions of students (set -1 interview) and follow-up questions from questionnaires and observation classes where the students' learning strategies can be directly monitored (set of interview-2) and connect it with field observations where students spend time outside of class hours.

\section{b) Classroom Observation Matrix:}

The next data collection method is a matrix that is designed to record the results of classroom observation tailored to the issues that will be studied. Through this method, some information can be obtained, especially to see the participation of students in a class that will directly represent models of learning strategies they use and their response to the exposure of the material from the lecturer.

\section{c) Note Fields (Results of field observations)}


During the research is in the field notes on aspects that support the object of research will continue to be updated. This will help researchers to collect data on student learning strategies when outside the classroom. Gathered for the study, and most importantly, they are considered as social facts that are produced, shared and used in wider community". Thus, they are acknowledged as a reliable source of data. 4. Data Analysis. All data collected through the research instrument has been stated previously except questionnaire will be compiled, transcribed, interpreted and analyzed descriptively qualitative. Questionnaire will be computed and analyzed quantitatively using SPSS to determine the frequency of use of learning strategies of students in relation to the achievement of the final value of their English. The qualitative analysis will be used mostly in reviewing the data that has been collected. Data collection and analysis will be done on-going direct to analyze the data that has been collected by following the procedures that had been developed previously. Analysis in question is an analysis of the early stages in between interpretation and categorizing data. This will allow researchers to determine the scope of the study as early as possible. Qualitative analysis in this study will use NVivo software (Gibbs, 2002), a technology innovation that serves as software for data storage and retrieval (deposit and withdrawal data) specifically for qualitative data. Once the data is transcribed researchers interpret data will be analyzed using NVivo and integrate into the discussion of the findings (finding) as a whole to address the problem formulation (research questions). Artifacts or documents is an important tool and are very reliable in the study. This is possible because the document is written data that can be generated and known even used by the general public in the community at large. Documents required for this study is documentation of local culture in the form of artifacts, text, etc. In addition, the value of pre-test and post-test of the studied sample will also be collected to see progress or their progress during the course of skills in their respective faculties.

\section{Concluding Remarks}

Regarding the students' attitudes and perceptions towards ICT in improving the SCL methods, data shows some significant results. One of those is that the majority of students agree that the multimedia environment of the Internet (e.g. text, image, sound, and video) helps them to understand online English materials. Other than that, they confirmed that the Internet can let them access more updated English materials. In other words, there were merely very little number of people who tended to reject the use of the internet due to some reason.

The students' expectations towards the ICT use in English learning are quite interesting. There are 23 students out of 30 agreed to hope that the use of ICT will help them to learn English more efficiently. In addition, they hope they can access information about English speaking countries directly via Internet and also the ICT can be used throughout their university life. They further expect that the use of ICT can be used to provide more interactive activities for students and to learn more about foreign culture via the Internet.

To be more precise, the findings suggest that students perceived benefits of using blogs included increased interest and motivation to use English because of interaction with, and feedback from, classmates and teacher. The findings also recommend that students were interested in continuing to blog even after the semester finished. Further research needs to focus on whether or not students did indeed continue using this resource after the course ended. They also agree that the Internet can let them get more direct information from English speaking countries. Most importantly, they really enjoy the writing through weblog.

\section{References}

AECT. (1977). The definition of educational technology. Washington DC: AECT.

Aswad, M., Rahman, F., Said, I. M., Hamuddin, B., \& Nurchalis, N. F. (2019). A Software to Increase English Learning Outcomes: An Acceleration Model of English as the Second Language. The Asian EFL Journal, 26(6.2), 2019.

Gibbs, G. (2002) Qualitative data analysis: Explorations with NVivo. Open University Press, Buckingham

Hamuddin, B., Rahman, F., Pammu, A., Sanusi Baso, Y., \& Derin, T. (2020). Cyberbullying Among EFL Students' blogging Activities: Motives And Proposed Solutions. Teaching English with Technology, 20(2), 3-20.

Januszewski, A. (2001) Educational technology: The development of a concept. Englewood, CO:Libraries Unlimited.

Junaidi, J. et al (2020a). ICT usage in teaching English in Pekanbaru: Exploring junior high school teachers' problems. International Journal of Advanced Science and Technology, 29(3), 5052-5063.

Junaidi, J. et al. (2020b). Artificial Intelligence in EFL Context: Rising Students' Speaking Performance with Lyra Virtual Assistance. International Journal of Advanced Science and Technology Rehabilitation, 29(5), 6735-6741. 
Lee, S. J., \& Reeves, T. C. (2007). Edgar Dale: A significant contributor to the field of educational technology. Educational Technology, 47(6), 56.

Miftachudin (2017). Use of Blogs in English Language Learning.REGISTER JOURNAL, Language \& Language Teaching Journals.Vol. 10, No. 1, 2017, pp.101-121

Rahman, F. (2017). Cyber literature: A reader-writer interactivity. International Journal of Social Sciences \& Educational Studies, 3(4), 156.

Rosenberg, M. J. (2001). E-Learning: strategies for delivering knowledge in the digital age. New York, NY: McGraw-Hill Companies, Inc 